Check for updates

Cite this: RSC Adv., 2017, 7, 18553

Received 2nd March 2017

Accepted 22nd March 2017

DOI: $10.1039 / \mathrm{c} 7 \mathrm{ra02575k}$

rsc.li/rsc-advances

\title{
Synthesis of silver-anchored polyaniline-chitosan magnetic nanocomposite: a smart system for catalysis
}

\author{
Mohamad M. Ayad, (DD *ab Wael A. Amer, (D) a Mohammed G. Kotp, ${ }^{\text {a }}$ Islam M. Minisy, (D) \\ Ahmed F. Rehab, ${ }^{a}$ Dušan Kopeckýc and Přemysl Fitl ${ }^{c}$
}

A simple route was employed for the fabrication of a polyaniline (PANI)-chitosan (CS)-magnetite $\left(\mathrm{Fe}_{3} \mathrm{O}_{4}\right)$ nanocomposite (PANI-CS- $\mathrm{Fe}_{3} \mathrm{O}_{4}$ ) via the in situ polymerization of aniline in the presence of CS using anhydrous iron(III) chloride as an oxidizing agent. The magnetic character of the nanocomposite results from the presence of iron oxide nanoparticles, which were formed as side products during the synthesis of the PANI-CS nanocomposite. The synthesized PANI-CS- $\mathrm{Fe}_{3} \mathrm{O}_{4}$ nanocomposite was fully characterized using Fourier transform infrared (FTIR) spectroscopy, X-ray diffraction (XRD), energy dispersive X-ray (EDX), scanning electron microscopy (SEM), transmission electron microscopy (TEM) and vibrating sample magnetometry (VSM). The reduction of silver nitrate by the synthesized nanocomposite enables the anchoring of silver (Ag) nanoparticles onto its surface. The catalytic properties of the Ag-decorated nanocomposite (AgaPANI-CS- $\mathrm{Fe}_{3} \mathrm{O}_{4}$ ) toward the reduction of 4-nitrophenol was investigated using sodium borohydride as a reducing agent.
\end{abstract}

\section{Introduction}

In recent years, noble metal nanoparticles have attracted remarkable attention in different fields of human activities such as thermal therapy, optoelectronics, biological imaging, sensors, biomedicine, energy conversion and catalysis ${ }^{1-5}$ due to their extraordinary chemical, physical and biological properties. The properties and hence the efficacy of these metal nanoparticles depend mainly on their size. ${ }^{6-8}$ Furthermore, there is a growing interest in developing nanoparticles for the catalysis of different types of reactions due to their high specific surface as well as the catalytic performance, which was found to gradually increase with decreasing nanoparticle size. ${ }^{6,9}$ Silver nanoparticles are especially important due to their relative abundance, low cost, high electrical and thermal conductivity, high resistance to oxidation and antimicrobial effects, resulting in their application in the textile industry, food additives, plastics and packaging and for medical instruments and burn dressings. ${ }^{10}$ On the other hand, silver nanoparticles have a disadvantage in their aggregation leading to large size aggregates; hence low catalytic efficiency is obtained. To prevent their aggregation, ${ }^{\mathbf{1 1}}$ researchers aim their efforts to reduce silver nanoparticles on the surface of different

${ }^{a}$ Chemistry Department, Faculty of Science, Tanta University, Tanta 31527, Egypt. E-mail: mohamad.ayad@ejust.edu.eg; Fax: +20 3 4599520; Tel: +20 34599520

${ }^{b}$ School of Basic and Applied Sciences, Egypt-Japan University of Science and Technology, New Borg El-Arab City, Alexandria 21934, Egypt

'Department of Physics and Measurements, Faculty of Chemical Engineering, University of Chemistry and Technology, 16628 Prague, Czech Republic conducting polymers or their nanocomposites such as polyaniline (PANI)-graphene nanocomposite. ${ }^{\mathbf{1 2}}$

Chitosan (CS) is one of the most popular natural biopolymers and is considered to be the second most widespread polymer in nature after cellulose. CS is a linear $\beta$-1,4-linked polysaccharide and it is the product of chitin deacetylation. ${ }^{\mathbf{1 3}}$ CS is a cationic polymer that possesses chelating ability due to the presence of active amino and hydroxyl functional groups. The ultimate properties e.g. non-toxicity, good water permeability, high mechanical strength, adhesion, biocompatibility, biological activities such as induced disease resistance in plants and antimicrobial effect ${ }^{14}$ were the motivation for the application of CS in different fields such as medicine, pharmaceutical industry, food production, plant growing and chemical engineering. ${ }^{\mathbf{1 3 , 1 5 - 1 7}}$ Despite all these good and attractive properties, CS has relatively poor stability and thus its nanocomposites with other polymers of high stability (such as conducting polymers) were fabricated to make way towards new possible applications. ${ }^{17-21}$

Recently, conducting polymers such as PANI, polypyrrole, polyacetylene, polyethylene dioxythiophene have been studied by many researchers in different fields as a result of their $\pi$ conjugated structures and promising properties. ${ }^{22-24}$ PANI has a special position among these polymers due to its unique properties such as ease of preparation, high conductivity, chemical and environmental stability under ambient conditions, low operational voltage in addition to its unique redox properties ${ }^{25,26}$ which result in directing the research in the last 
years, to use PANI for different applications especially as catalyst supports. ${ }^{27-33}$

Researchers face a great problem during the separation of the products from the reaction medium; the traditional routes were filtration or centrifugation (especially for nanometer-scaled materials), which are time and energy consuming. ${ }^{34,35}$ Magnetic separation is one of the most promising techniques in separation that has excellent advantages over other methods including high speed, accuracy, ease of control as well as simplicity. ${ }^{36}$ Recently, a magnetic chitosan-polypyrrole-magnetite nanocomposite was prepared and employed as an impressive adsorbent of an anionic dye from aqueous solution. ${ }^{37}$

In this work, a facile one step method for the preparation of magnetic nanocomposite (PANI-CS- $\mathrm{Fe}_{3} \mathrm{O}_{4}$ ) using PANI, CS and magnetite $\left(\mathrm{Fe}_{3} \mathrm{O}_{4}\right)$ is presented. Subsequently, this nanocomposite acts as a reducing agent for silver nitrate to get silver nanoparticles anchored onto its surface. ${ }^{31,38}$ The synthesized

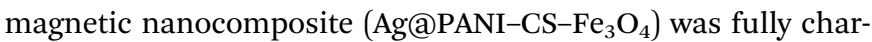
acterized via different analysis techniques including FTIR, XRD, SEM, TEM and EDX. The catalytic effect of the synthesized nanocomposite was examined for the reduction of one of the most hazardous and toxic nitroaromatic compounds (4-nitrophenol (4-NP)), which are widely used in different industries. ${ }^{39}$

\section{Experimental}

\subsection{Chemicals}

Aniline (Adwic, Egypt) was distilled twice over zinc dust. ${ }^{40}$ Acetic acid (Adwic, Egypt), chitosan (Acros, USA, molecular weight: 100 000-300 000), anhydrous $\mathrm{FeCl}_{3} 98 \%$ (SISCO, India), $\mathrm{NaOH}$ pellets (Loba Chemie, India) were used as received. Sodium boron hydride $\left(\mathrm{NaBH}_{4}\right)$ (Johnson Matthey, UK), silver nitrate (BDH, UK), 4-nitrophenol (4-NP) (Sigma Aldrich) were used without further purification. Double distilled water was used for all preparations.

\subsection{Synthesis of PANI}

PANI was fabricated according to the previous protocol reported by Ayad et al. ${ }^{41}$ Briefly, $0.05 \mathrm{M}$ of aniline monomer was dissolved in $50 \mathrm{~mL}$ of $0.1 \mathrm{M} \mathrm{HCl}$ with stirring till complete dispersion and homogeneity. $50 \mathrm{~mL}$ of anhydrous $\mathrm{FeCl}_{3}$ solution $(0.154 \mathrm{M})$ was added dropwise to the aniline solution with stirring for 3 hours. The resulting PANI was washed 3 times by distilled water then it was finally washed with methanol. The polymer was left to dry at $50{ }^{\circ} \mathrm{C}$ overnight.

\subsection{Synthesis of PANI-CS- $\mathrm{Fe}_{3} \mathrm{O}_{4}$ nanocomposite}

The synthesis of PANI-CS- $\mathrm{Fe}_{3} \mathrm{O}_{4}$ nanocomposite was performed according to the procedures reported by Ayad et al. ${ }^{16} 1 \mathrm{~g}$ of CS was dissolved into $100 \mathrm{~mL}$ of $2 \% \mathrm{v} / \mathrm{v}$ acetic acid then $0.5 \mathrm{~mL}$ of aniline monomer was added. The resulting solution was left under stirring for 1 hour to homogenize it. In an ice bath, $2.51 \mathrm{~g}$ of anhydrous $\mathrm{FeCl}_{3}$ was added to the mixture and left under mechanical stirring overnight. $25 \mathrm{~mL}$ of $0.5 \mathrm{M} \mathrm{NaOH}$ solution was added dropwise to the mixture. The resulting product was collected and washed several times with distilled water and ethanol. Eventually, the product was dried in an oven at $50{ }^{\circ} \mathrm{C}$ overnight.

\subsection{Synthesis of Ag nanoparticles@PANI-CS- $\mathrm{Fe}_{3} \mathrm{O}_{4}$ nanocomposite}

PANI-CS- $\mathrm{Fe}_{3} \mathrm{O}_{4}$ nanocomposite was added to $50 \mathrm{~mL}$ of $0.1 \mathrm{M}$ $\mathrm{NH}_{4} \mathrm{OH}$ for full deprotonation, then it was washed with distilled water. $0.2 \mathrm{~g}$ of the previously deprotonated PANI-CS- $\mathrm{Fe}_{3} \mathrm{O}_{4}$ nanocomposite was added to $50 \mathrm{~mL}$ of $3 \mathrm{mM}$ of $\mathrm{AgNO}_{3}$ under mechanical stirring for 3 hours. The product was washed with distilled water and ethanol several times. Finally, it was dried at room temperature for 2 days.

\subsection{Catalytic activity of Ag@PANI-CS- $\mathrm{Fe}_{3} \mathrm{O}_{4}$}

In a well stoppered quartz cuvette, $2.5 \mathrm{~mL}$ of $7 \mathrm{mM}$ of alkaline solution of 4-NP was added to $1 \mathrm{mg}$ of $\mathrm{Ag} @ P A N I-C S-\mathrm{Fe}_{3} \mathrm{O}_{4}$ nanocomposite and the UV-VIS absorption spectra were recorded. Afterwards, $0.5 \mathrm{~mL}$ of $10 \mathrm{mg} \mathrm{mL}{ }^{-1}$ of $\mathrm{NaBH}_{4}$ was added to the previous solution and the reaction progress was followed by measuring the UV-VIS absorption spectra over time.

\subsection{Characterization}

XRD patterns of the prepared samples were measured by X-ray diffractometer (GNR APD-2000 PRO) with $\mathrm{CuK} \alpha$ radiation (40 $\mathrm{kV}, 30 \mathrm{~mA}$ ) in the step scan mode. Elemental composition of the prepared samples was determined by EDX spectrometer (Bruker Quantax 200 with XFlash 6|10 detector) at $15 \mathrm{kV}$ of accelerating voltage. A Bruker Tensor 27 FTIR (with the frequency range of $4000-400 \mathrm{~cm}^{-1}$ ) was used to record functional groups and also to record the finger print regions in different steps of the nanocomposite preparation. SEM images were captured on Tescan Mira $3 \mathrm{LMH}$ at accelerating voltage of $30 \mathrm{kV}$. TEM (JEM$2100 \mathrm{~F}$ ) at $200 \mathrm{kV}$ was used for morphology measurements. UVVIS absorption spectra were recorded using UVD-2960 (Labomed Inc.) spectrometer. Magnetic properties were measured by vibrating sample magnetometer (VSM) on physical property measurement system (Quantum Design).

\section{Results and discussion}

Two steps-based simple method was used for synthesizing $\mathrm{Ag} @ P A N I-C S-\mathrm{Fe}_{3} \mathrm{O}_{4}$ nanocomposite. In situ chemical polymerization of aniline was performed using $\mathrm{FeCl}_{3}$ as an oxidant in presence of CS. During polymerization, iron(III) chloride was reduced into iron(II) chloride. In addition, sodium hydroxide solution was added to the previous solution to produce hydroxides of $\mathrm{Fe}^{2+}$ and $\mathrm{Fe}^{3+}$ ions $\left[\mathrm{Fe}(\mathrm{OH})_{2}\right.$ and $\left.\mathrm{Fe}(\mathrm{OH})_{3}\right]$, which resulted in the formation of $\mathrm{Fe}_{3} \mathrm{O}_{4}$ nanoparticles (as shown in Scheme 1) that grants the nanocomposite with magnetic character. ${ }^{16}$ The classical synthesis of $\mathrm{Fe}_{3} \mathrm{O}_{4}$ via co-precipitation method in $\mathrm{pH}$ range between 8 and 12 was followed through reaction of stoichiometric ratio of $2: 1\left(\mathrm{Fe}^{3+} / \mathrm{Fe}^{2+}\right)$ ions as ascribed in eqn (1). ${ }^{42}$ The inclusions of magnetic $\mathrm{Fe}_{3} \mathrm{O}_{4}$ particles facilitate the separation process. $\mathrm{NH}_{4} \mathrm{OH}$ was used to make and ensure the deprotonation process of PANI-CS- $\mathrm{Fe}_{3} \mathrm{O}_{4}$ nanocomposite in order to activate the lone pair of electrons located 


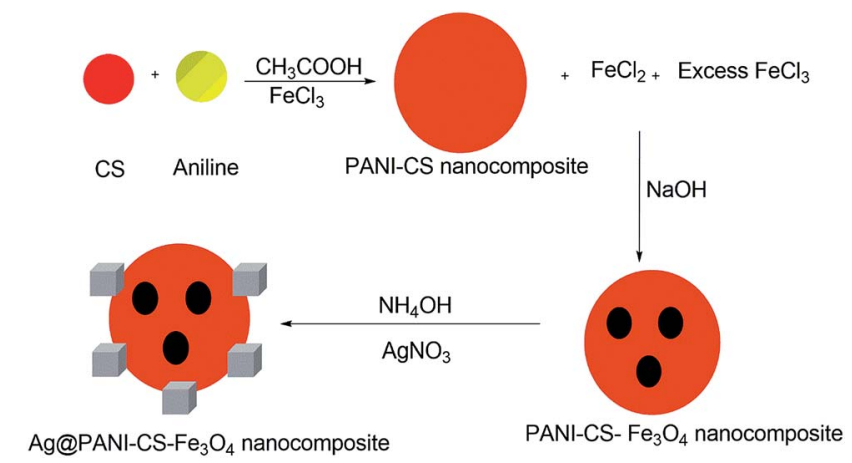

Scheme 1 The formation mechanism of AgaPANI-CS- $\mathrm{Fe}_{3} \mathrm{O}_{4}$ nanocomposite.

at amino, imino and hydroxyl groups in polyaniline and chitosan which facilitates the coordination of $\mathrm{Ag}$ ions onto these basic active sites.

$$
\mathrm{Fe}^{2+}+2 \mathrm{Fe}^{3+}+8 \mathrm{OH}^{-} \rightarrow \mathrm{Fe}_{3} \mathrm{O}_{4}+4 \mathrm{H}_{2} \mathrm{O}
$$

Generally, reducing agents such as hydrazine and sodium citrate were used for anchoring silver nanoparticles over some surfaces..$^{43}$ These reductants may cause many problems such as toxicity of a product. ${ }^{44}$ In the present study, silver ions were reduced via PANI to silver nanoparticles onto the nanocomposite surface. ${ }^{45}$ Furthermore, CS has an affinity toward silver ions as a result of its primary amines and hydroxyl groups which chelates with the metal cation. ${ }^{46}$

The chemical structures of PANI, CS, and the magnetic nanocomposite PANI-CS- $\mathrm{Fe}_{3} \mathrm{O}_{4}$ before and after anchoring the silver nanoparticles were investigated by measuring their FTIR spectra. Fig. 1 shows the comparison of the FTIR spectra of PANI-CS- $\mathrm{Fe}_{3} \mathrm{O}_{4}$ (Fig. 1C) and Ag@PANI-CS-Fe $\mathrm{O}_{4}$ (Fig. 1D) with the FTIR spectra of PANI (Fig. 1A) and CS (Fig. 1B). The main peaks of PANI appear at $1571 \mathrm{~cm}^{-1}, 1472 \mathrm{~cm}^{-1}, 1301 \mathrm{~cm}^{-1}, 1121$ $\mathrm{cm}^{-1}$ and $803 \mathrm{~cm}^{-1}$ (Fig. 1A) which are attributed to nitrogen quinone (Q) structure, benzene ring (B) structure vibration, $\mathrm{C}-\mathrm{N}$ stretching vibration, in plane $\mathrm{C}-\mathrm{H}$ vibration and out-of-plane $\mathrm{C}-\mathrm{H}$ bending vibrations, respectively. ${ }^{33,47,48}$ The saccharide structure of CS biopolymer is represented by the peaks at 3440 $\mathrm{cm}^{-1}, 1655 \mathrm{~cm}^{-1}, 1372 \mathrm{~cm}^{-1}, 2861 \mathrm{~cm}^{-1}, 1155 \mathrm{~cm}^{-1}$ and 1070 $\mathrm{cm}^{-1}$ (Fig. 1B) that are related to its stretching $\mathrm{NH}_{2}$ groups, bending $\mathrm{NH}_{2}$, vibrational alcoholic groups $\mathrm{C}-\mathrm{OH}$, bending $\mathrm{C}-$ $\mathrm{OH}$, anti-symmetric bending of $\mathrm{C}-\mathrm{O}-\mathrm{C}$ bridge and vibrational C-O, respectively. ${ }^{18,49}$ The FTIR spectrum of PANI-CS- $\mathrm{Fe}_{3} \mathrm{O}_{4}$ nanocomposite (Fig. 1C) exhibits broadening between 3435 $\mathrm{cm}^{-1}$ and $2826 \mathrm{~cm}^{-1}$ which indicates the hydrogen bond interaction between PANI and CS. ${ }^{18,50}$ Moreover, the disappearance of CS band at $1654 \mathrm{~cm}^{-1}$ (Fig. 1B) accompanied by appearance of new one at $1636 \mathrm{~cm}^{-1}$ for PANI-CS- $\mathrm{Fe}_{3} \mathrm{O}_{4}$ nanocomposite (Fig. 1C) is an effective indication for the interaction between PANI and CS. ${ }^{16}$ In addition, presence of pristine magnetite is usually associated with presence of two peaks at $580 \mathrm{~cm}^{-1}$ and $464 \mathrm{~cm}^{-1} .^{51,52}$ In Fig. 1C, the new peaks at $595 \mathrm{~cm}^{-1}$ and $449 \mathrm{~cm}^{-1}$ support the presence of magnetite and

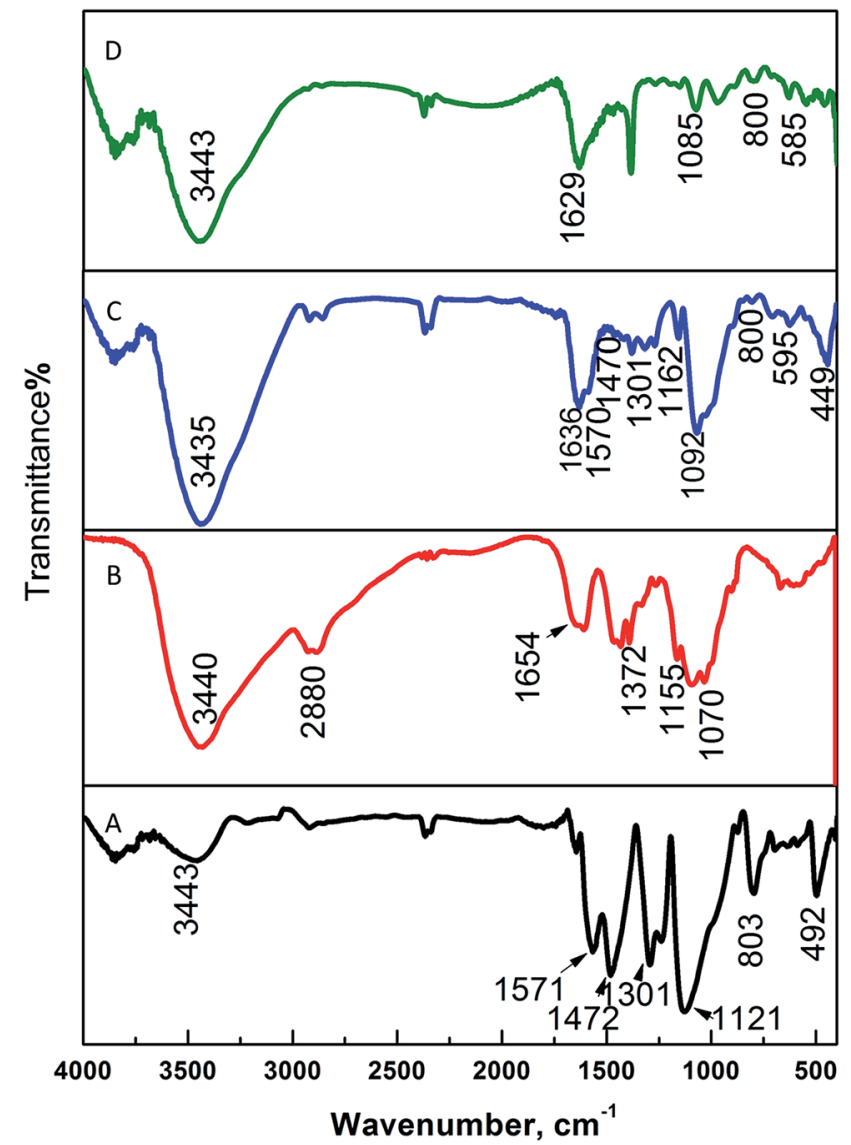

Fig. 1 FTIR spectra of PANI (A), CS (B), PANI-CS- $\mathrm{Fe}_{3} \mathrm{O}_{4}$ nanocomposite (C), and Ag(aPANI-CS- $\mathrm{Fe}_{3} \mathrm{O}_{4}$ nanocomposite (D).

are related to vibrational $\mathrm{Fe}-\mathrm{O}$ bond..$^{51,53}$ The shifting of the magnetite peaks from that of parent magnetite peak indicates the interaction of magnetite with PANI and CS particles. Track D shows the finger print of track $\mathrm{C}$ with small shift of $\mathrm{NH}$ and $\mathrm{OH}$ peaks position from $1636 \mathrm{~cm}^{-1}$ and $3435 \mathrm{~cm}^{-1}$ (Fig. 1C) to 1629 $\mathrm{cm}^{-1}$ and $3343 \mathrm{~cm}^{-1}$ (Fig. 1D) due to silver metal reduction its deposition over PANI-CS- $\mathrm{Fe}_{3} \mathrm{O}_{4}$ nanocomposite. The wavenumber shift caused by anchoring silver was observed in the literatures by many authors. ${ }^{46,54}$ Therefore, FTIR suggest good

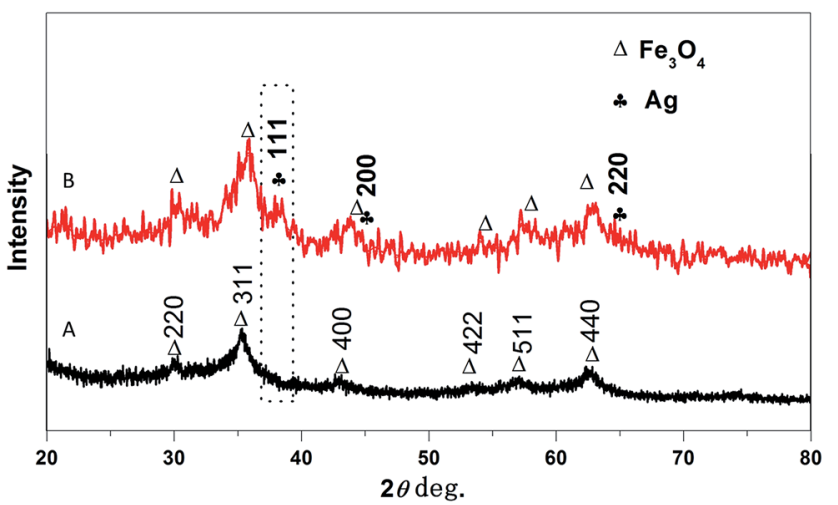

Fig. 2 XRD patterns of the prepared PANI-CS- $-\mathrm{Fe}_{3} \mathrm{O}_{4}$ (A) and $\mathrm{Ag}\left(\mathrm{PANI}-\mathrm{CS}-\mathrm{Fe}_{3} \mathrm{O}_{4}\right.$ (B) nanocomposites. 


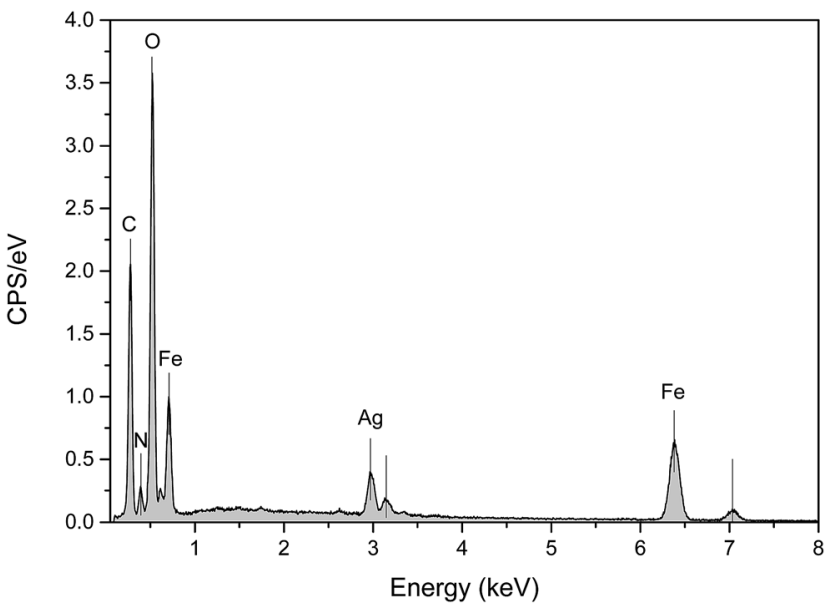

Fig. 3 EDX of $\mathrm{Ag}\left(\mathrm{PANI}-\mathrm{CS}-\mathrm{Fe}_{3} \mathrm{O}_{4}\right.$.

Table 1 Average of elements masses in the AgaPANI-CS- $\mathrm{Fe}_{3} \mathrm{O}_{4}$ nanocomposite

\begin{tabular}{lccr}
\hline Element & Mass norm. \% & & Average \\
\hline Measurement no. & 1 & 2 & \\
Oxygen & 39.609918 & 38.52287 & 39.07 \\
Iron & 28.744685 & 33.317434 & 31.03 \\
Carbon & 21.980049 & 18.941147 & 20.46 \\
Silver & 6.1181148 & 6.8474 & 6.48 \\
Nitrogen & 3.5472337 & 2.3710902 & 2.96 \\
& 100 & 100 & 100
\end{tabular}

interaction between CS and PANI, the presence of magnetite and the deposition of silver metal nanoparticles on the PANI$\mathrm{CS}-\mathrm{Fe}_{3} \mathrm{O}_{4}$ nanocomposite.

$\mathrm{X}$-ray diffraction (XRD) helps to identify the crystallinity and phase of the product. Fig. 2A exhibits the XRD pattern of the prepared nanocomposite $\mathrm{PANI}-\mathrm{CS}-\mathrm{Fe}_{3} \mathrm{O}_{4}$ which represents the diffraction patterns of $\mathrm{Fe}_{3} \mathrm{O}_{4}$ that can be indexed to $(h k l)$ reflection peaks of [220], [311], [400], [422], [511] and [440] at $2 \theta$ equivalent to $30.2^{\circ}, 35.74^{\circ}, 43.12^{\circ}, 53.51^{\circ}, 57.19^{\circ}$ and $62.78^{\circ}$, respectively for face centered cubic (FCC) phase of magnetite. ${ }^{53,55,56}$ Track B represents PANI-CS- $\mathrm{Fe}_{3} \mathrm{O}_{4}$ nanocomposite after formation of silver nanoparticles over its surface. Three main diffraction lines were observed at $2 \theta$ of $38.2^{\circ}, 44.1^{\circ}$ and $64.5^{\circ}$ that can be indexed with $(h k l)$ crystallographic planes to [111], [200] and [220], respectively and related to FCC silver crystals. $^{\text {57-59 }}$ These XRD data match with FTIR spectra and therefore they prove the presence of magnetite and silver nanoparticles on the PANI-CS- $\mathrm{Fe}_{3} \mathrm{O}_{4}$ nanocomposite.

The EDX spectra of $\mathrm{Ag} @ \mathrm{PANI}-\mathrm{CS}-\mathrm{Fe}_{3} \mathrm{O}_{4}$ nanocomposite were measured to identify the chemical composition (Fig. 3). The analysis result reveals the presence of oxygen, iron, carbon, silver and nitrogen. The average of mass percentages of the elements were determined and calculated twice and then cited in Table 1.

The morphology and the size distribution of the nanocomposite were determined using the SEM technique. Fig. 4A shows the typical SEM image of Ag@PANI-CS- $\mathrm{Fe}_{3} \mathrm{O}_{4}$ nanocomposite. The image reveals the nanostructure of the synthesized nanocomposite and the spherical shape of the $\mathrm{Fe}_{3} \mathrm{O}_{4}-\mathrm{Ag}$

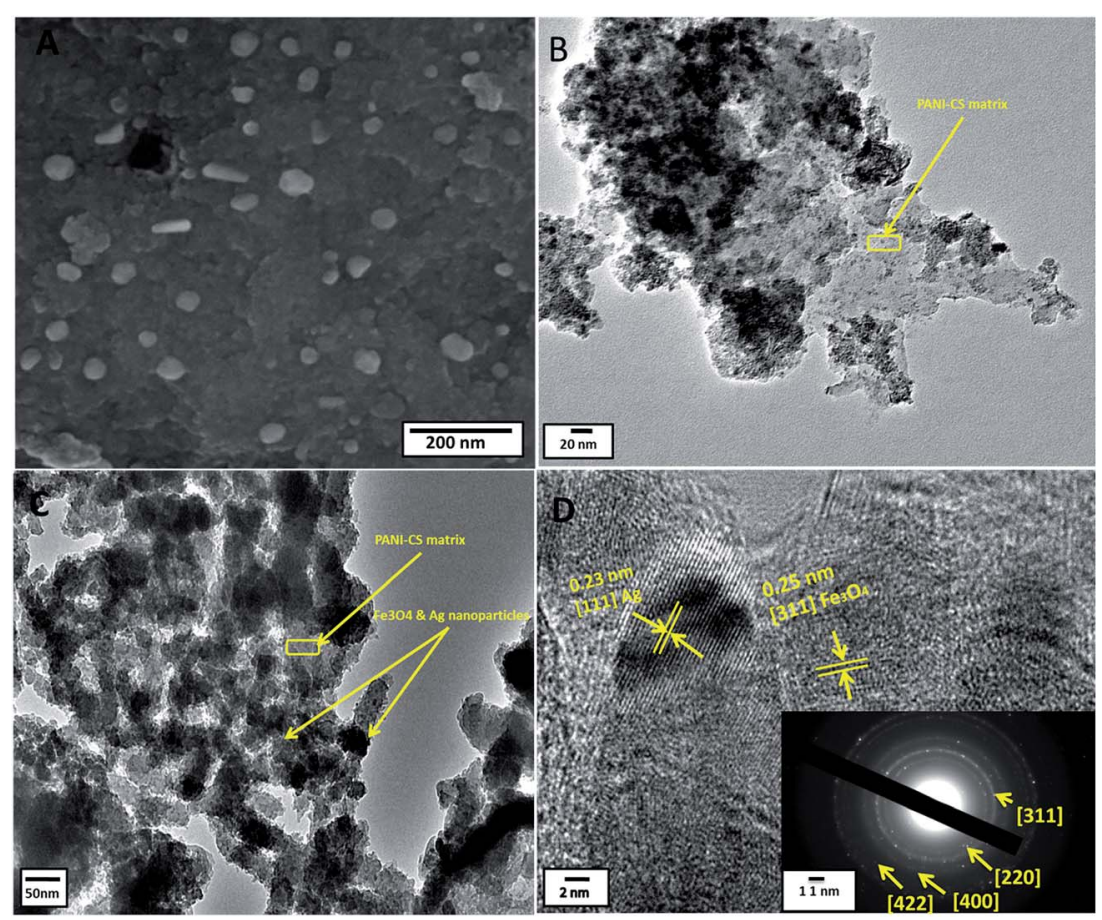

Fig. $4 \mathrm{SEM}$ of $\mathrm{Ag}\left(\mathrm{PANI}-\mathrm{CS}-\mathrm{Fe}_{3} \mathrm{O}_{4}\right.$ nanocomposite (A), TEM images of PANI-CS- $\mathrm{Fe}_{3} \mathrm{O}_{4}$ nanocomposite (B) and Ag@PANI-CS-Fe $3 \mathrm{O}_{4}$ nanocomposite (C), and HRTEM of AgaPANI-CS- $\mathrm{Fe}_{3} \mathrm{O}_{4}$ nanocomposite (D). The inset shows SAED of $\mathrm{Ag}\left(\mathrm{PPANI}-\mathrm{CS}-\mathrm{Fe}_{3} \mathrm{O}_{4}\right.$ nanocomposite. 
nanostructures (without aggregation) on PANI-CS matrix with particle size of about 30-50 $\mathrm{nm}$.

The structure features of Ag@PANI-CS- $\mathrm{Fe}_{3} \mathrm{O}_{4}$ nanocomposite were investigated via the TEM technique. The TEM image of PANI-CS- $\mathrm{Fe}_{3} \mathrm{O}_{4}$ nanocomposite (Fig. 4B) shows the dispersion of $\mathrm{Fe}_{3} \mathrm{O}_{4}$ nanoparticles through PANI-CS matrix with low aggregation at high magnification. Fig. 4C is the TEM image of $\mathrm{Ag} @ P A N I-C S-\mathrm{Fe}_{3} \mathrm{O}_{4}$ nanocomposite; it shows uniform distribution of $\mathrm{Fe}_{3} \mathrm{O}_{4}-\mathrm{Ag}$ nanostructures accompanied with low aggregation to some extent. The typical HRTEM image of $\mathrm{Ag} @ \mathrm{PANI}-\mathrm{CS}-\mathrm{Fe}_{3} \mathrm{O}_{4}$ nanocomposite (Fig. 4D) shows that the nanoparticles are crystalline as the lattice fringes spacing are $0.25 \mathrm{~nm}$, which is consistent with the crystal structure of $\mathrm{Fe}_{3} \mathrm{O}_{4},{ }^{60}$ and also $0.23 \mathrm{~nm}$ revealing the crystal structure of $\mathrm{Ag}$ nanoparticles. ${ }^{61}$ The inset image exhibits the selected area via electron diffraction (SAED) of Ag@PANI-CS- $\mathrm{Fe}_{3} \mathrm{O}_{4}$ nanocomposite, which shows arrays with bright circles confirming the crystallinity of these nanoparticles that is consistent with the data obtained from XRD.

Vibrating sample magnetometer (VSM) system was used to investigate the magnetic properties of the synthetized nanocomposite. Fig. 5 shows non-coercive force property or remanence values at room temperature indicating the ferromagnetic property of PANI-CS- $\mathrm{Fe}_{3} \mathrm{O}_{4} @ \mathrm{Ag}$ nanocomposite. Saturation mass magnetization (Ms) of the Ag@PANI-CS- $\mathrm{Fe}_{3} \mathrm{O}_{4}$ nanocomposite observed from Fig. 5 is 0.4 emu $^{-1}$ so Ag@PANI-CS$\mathrm{Fe}_{3} \mathrm{O}_{4}$ nanocatalyst can be separated easily from the reaction medium by applying external magnetic field.

The reduction reaction of 4-NP to 4-aminophenol (4-AP) was selected as an example for testing the catalytic activity of $\mathrm{Ag} @ \mathrm{PANI}-\mathrm{CS}-\mathrm{Fe}_{3} \mathrm{O}_{4}$ nanocomposite. 4-NP can be reduced through $\mathrm{NaBH}_{4}$ (the hydrogen source for reduction reaction) as a reducing agent to 4-AP. Without catalyst, the color of 4-NP does not change with time. Therefore, noble metals or their nanocomposites are required as catalysts to accelerate the transfer of electrons from the electron donor $\left(\mathrm{BH}_{4}{ }^{-}\right)$to $4-\mathrm{NP}$ as the acceptor and in this case the reduction reaction ends in few minutes. ${ }^{39}$ The catalyzed reduction reaction was followed easily

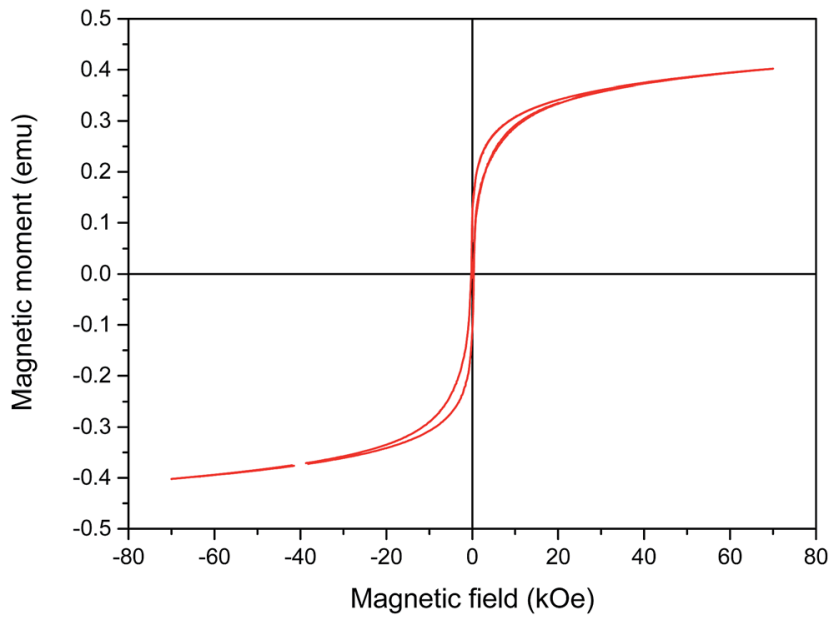

Fig. 5 Magnetic hysteresis loop (M-H) of $\mathrm{Ag}\left(\mathrm{PANI}-\mathrm{CS}-\mathrm{Fe}_{3} \mathrm{O}_{4}\right.$. via UV-VIS spectrophotometry since 4-NP has a characteristic absorption peak at $400 \mathrm{~nm}$ under alkaline conditions. The reduction of $4-\mathrm{NP}$ to 4 -AP is accompanied by change of the intense yellow color of 4-NP into colorless 4-AP solution with emergence of another peak at $310 \mathrm{~nm}$, which is related to 4-AP as shown in Fig. 6. ${ }^{62}$ Furthermore, the reduction in the concentration of 4-NP can be found by following the decrease of
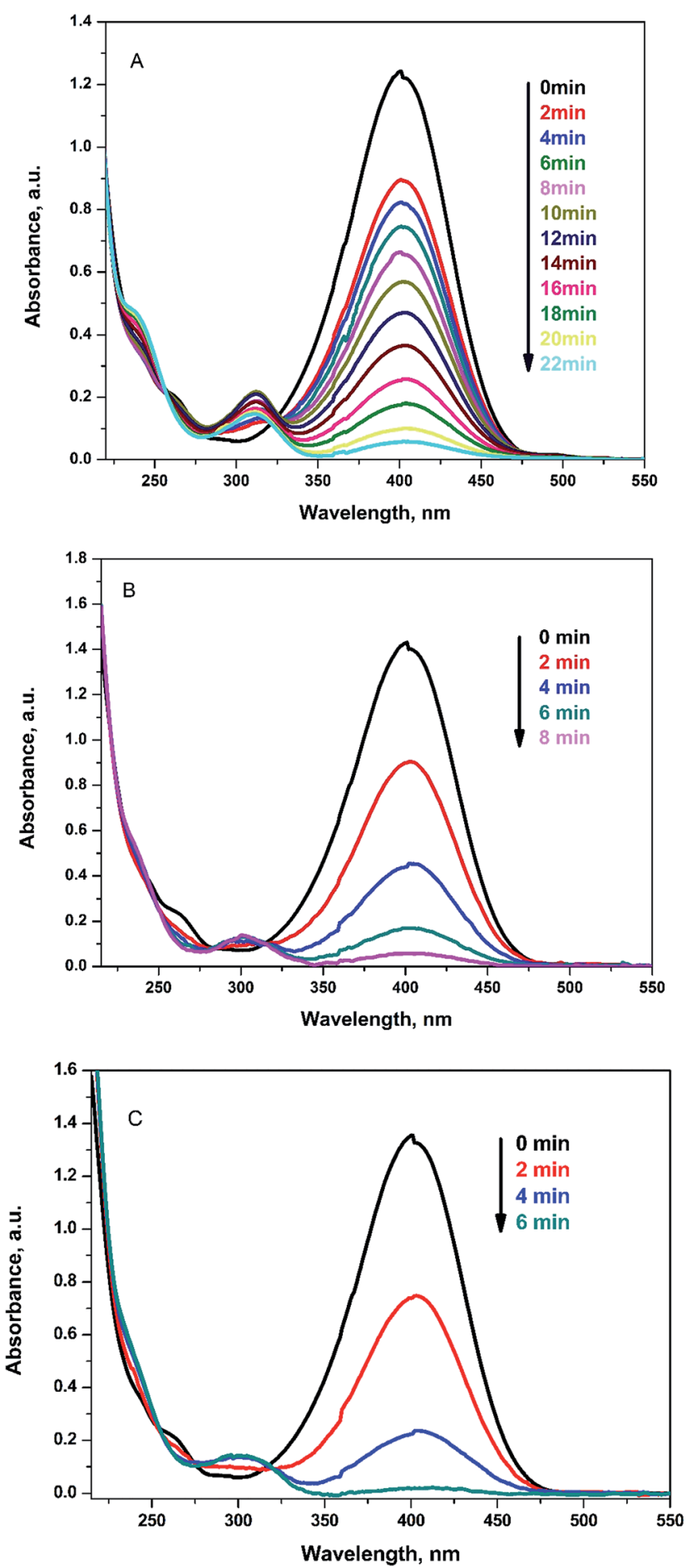

Fig. 6 UV-VIS spectra for reduction of 4-NP to 4-AP by $\mathrm{NaBH}_{4}$ using $1 \mathrm{mg}(\mathrm{A}), 2 \mathrm{mg}(\mathrm{B}), 3 \mathrm{mg}(\mathrm{C})$ of $\mathrm{Ag}\left(\mathrm{PANI}-\mathrm{CS}-\mathrm{Fe}_{3} \mathrm{O}_{4}\right.$ as a catalyst. 

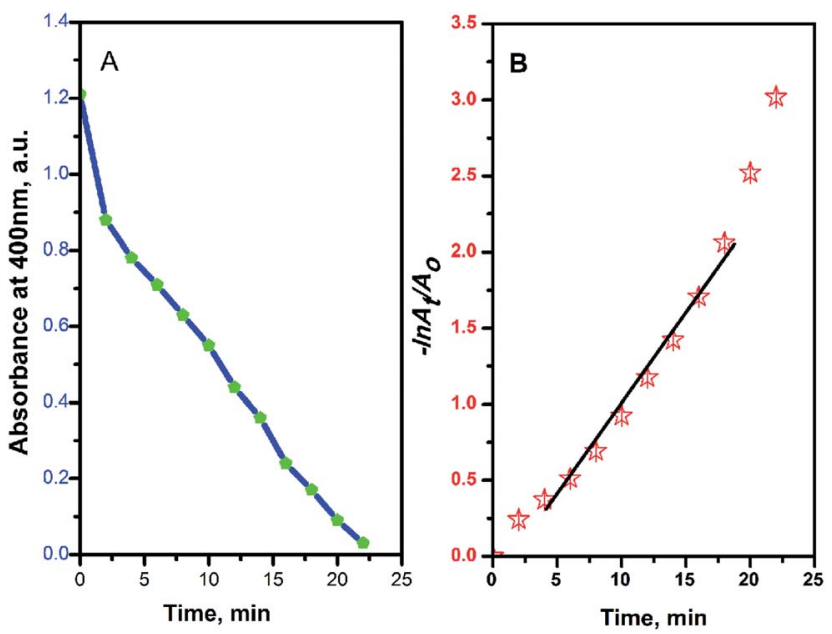

Fig. 7 Absorbance at $400 \mathrm{~nm}$ (A) and $-\ln A_{t} / A_{\circ}$ (B) versus the reduction reaction time of 4-NP by $\mathrm{NaBH}_{4}$ using $\mathrm{Ag} @ \mathrm{CPANI}-\mathrm{CS}-\mathrm{Fe}_{3} \mathrm{O}_{4}$ nanocomposite as a catalyst.

absorbance at $400 \mathrm{~nm}$ over time as shown in Fig. 6A. $1 \mathrm{mg}$ of $\mathrm{Ag} @ P A N I-C S-\mathrm{Fe}_{3} \mathrm{O}_{4}$ nanocomposite was used in the first period of the catalysis test and the reaction was ended within $22 \mathrm{~min}$ as shown in Fig. 6A and 7A. On using $2 \mathrm{mg}$ and $3 \mathrm{mg}$ of the fabricated catalyst, the reaction finished after only $8 \mathrm{~min}$ and 6 min, respectively as presented in Fig. 6B and C.

Due to the high concentration of the reducing agent $\mathrm{NaBH}_{4}$ compared to 4-NP, pseudo first order assumption was applied to calculate the kinetic rate of this reduction reaction. ${ }^{39,63}$ Fig. $7 \mathrm{~B}$ shows the linear relation between $-\ln A_{t} / A_{\mathrm{o}}$ over time, where $A_{\mathrm{o}}$ is the initial absorbance and $\mathrm{A}_{t}$ is absorbance at time $t$, to confirm the pseudo first order assumption.

Various metals anchored onto variety of substrates with their kinetic rates calculated from pseudo first order assumption were ascribed in Table 2. By comparing our system with other data reported for other systems in the literature, it can be found that a very small amount ( $1 \mathrm{mg}$ ) of $\mathrm{Ag} @ \mathrm{PANI}-\mathrm{CS}-\mathrm{Fe}_{3} \mathrm{O}_{4}$ nanocomposite (as compared to large amounts of other substrates) shows a very high catalytic efficacy toward the reduction of 4-NP as well as its ease of separation. This high catalytic activity may be attributed to the small size of silver nanoparticles that are uniformly distributed through the PANI-CS- $\mathrm{Fe}_{3} \mathrm{O}_{4}$ nanocomposite, which usually leads to high catalytic activity.

Low catalyst dose with high catalytic efficiency results from the presence of chelating sites in both PANI and CS represented in amino groups as well as hydroxyl groups which are entrapping more Ag nanoparticles leading to an increase in anchoring $\mathrm{Ag}$ metal onto a small weight of the catalyst. The ease of

Table 2 Comparison of Ag nanoparticles anchored onto various substrates with their kinetic rates

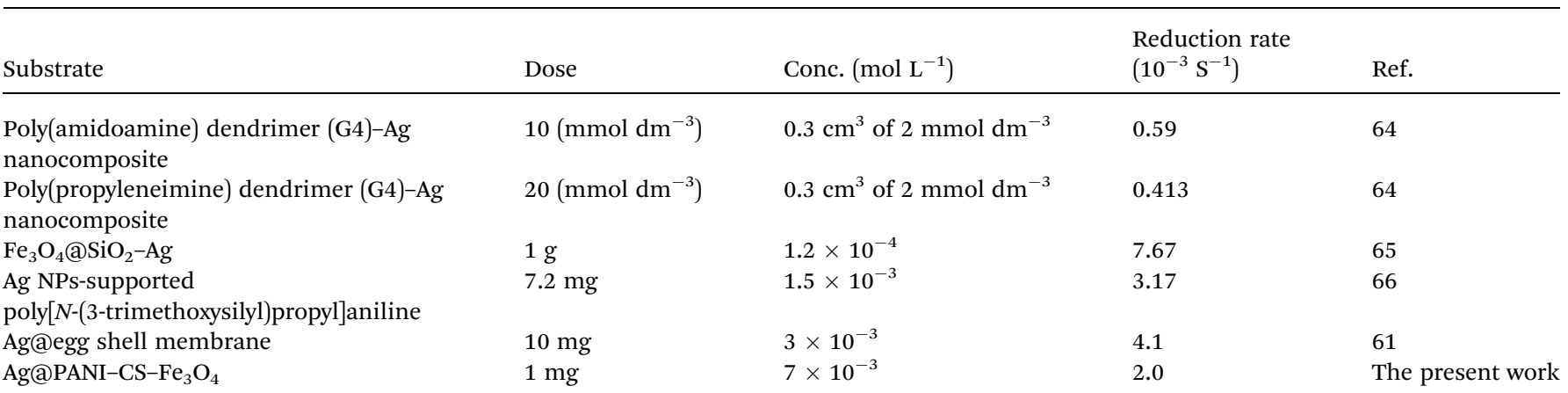
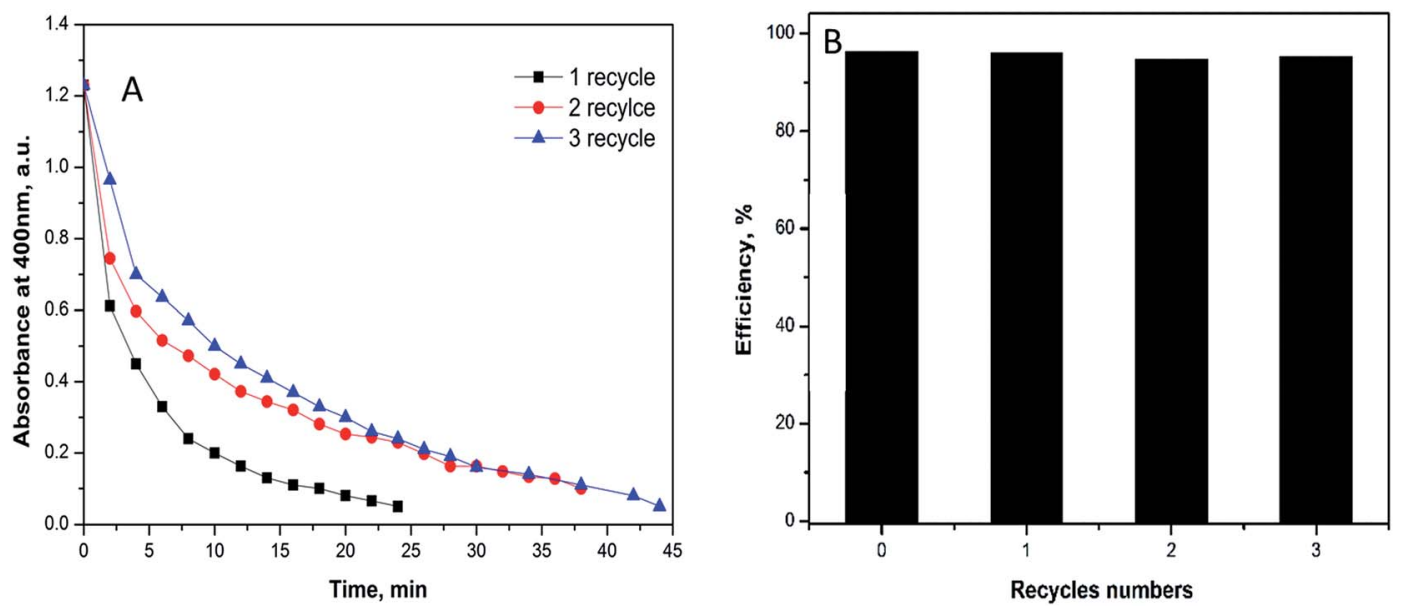

Fig. 8 Reusability of $1 \mathrm{mg}$ of $\mathrm{AgaPANI}-\mathrm{CS}-\mathrm{Fe}_{3} \mathrm{O}_{4}$ catalyst nanocomposite toward reduction of 4-NP via $\mathrm{NABH}$ as a reducing agent. 
separation of the catalyst (magnetically) and the low catalyst dose (1 mg) as compared to other catalyst systems (as seen in Table 2) which results a high catalytic rate is the main reason for calling this system a smart system.

The recovery of the catalyst was tested using $1 \mathrm{mg}$ of the fabricated catalyst under the similar above conditions. For the separation process, the substrate was exposed to magnetic field in the reaction cuvette and the produced aminophenol was drained quietly by syringe. The catalyst was recovered three times without great loss in the efficacy to prove that the catalyst is intact. In the first recycle, the reduction process ended at $25 \mathrm{~min}$ while the second and the third recycles last for 38 and 45 minutes, respectively (Fig. 8A). The time difference between the three recycles indicates the small decrease in the efficiency of the catalyst that could be attributed to the minor loss of the substrate during recycling.

The efficiency percentage $(\alpha)$ was calculated as reported by Zhang et al. ${ }^{67}$ according to eqn (2):

$$
\alpha=\frac{C_{\mathrm{o}}-C_{t}}{C_{\mathrm{o}}} \times 100 \%
$$

where, $C_{\mathrm{o}}$ is the initial concentration and $C_{t}$ is the concentration at the termination stage. Fig. 8B represents efficiency percentages for 4 successive cycles with efficacy more than $95 \%$ in the fourth cycle. This means that the same amount of the catalyst can be used many times with negligible loss in the catalytic efficacy.

\section{Conclusion}

In summary, PANI-CS- $\mathrm{Fe}_{3} \mathrm{O}_{4}$ nanocomposite was successfully prepared through simple steps method. The prepared nanocomposite acted as a green surface that was decorated with silver nanoparticles. The role of the substrate (PANI-CS nanocomposite) lies in the reducing power of PANI and the availability of amino, imino and hydroxyl groups in PANI and CS which facilitates the coordination of $\mathrm{Ag}$ ions onto these basic active sites. The Ag-anchored nanocomposite was fully characterized by FTIR, XRD, EDX, SEM, TEM and VSM. These characterizations proved successful formation of $\mathrm{Ag} @ P A N I-C S-\mathrm{Fe}_{3} \mathrm{O}_{4}$ nanocomposite with coarse particles of a spherical shape. The UVVisible spectrophotometry technique proved good catalytic efficacy of the prepared nanocomposite towards reduction of 4-NP. The new as-prepared nanocomposite from conducting polymer (PANI) and natural one (CS) with silver nanoparticles can be considered an eco-friendly catalyst that is characterized by its ease of preparation as well as its magnetic character (for ease of separation) and thus $\mathrm{Ag} @ \mathrm{PANI}-\mathrm{CS}-\mathrm{Fe}_{3} \mathrm{O}_{4}$ can be considered a promising catalysis candidate for industry and other fields.

\section{References}

1 L. C. Kennedy, L. R. Bickford, N. A. Lewinski, A. J. Coughlin, Y. Hu, E. S. Day, J. L. West and R. A. Drezek, Small, 2011, 7, 169-183.

2 A. Matschulat, D. Drescher and J. Kneipp, ACS Nano, 2010, 4, 3259-3269.
3 W. P. To, K. T. Chan, G. S. M. Tong, C. Ma, W. M. Kwok, X. Guan, K. H. Low and C. M. Che, Angew. Chem., Int. Ed., 2013, 52, 6648-6652.

4 S. Roy, G. Palui and A. Banerjee, Nanoscale, 2012, 4, 2734-2740.

5 B. N. Zope, D. D. Hibbitts, M. Neurock and R. J. Davis, Science, 2010, 330, 74-78.

6 T. Yao, C. Wang, J. Wu, Q. Lin, H. Lv, K. Zhang, K. Yu and B. Yang, J. Colloid Interface Sci., 2009, 338, 573-577.

7 B. Medasani, Y. H. Park and I. Vasiliev, Phys. Rev. B: Condens. Matter Mater. Phys., 2007, 75, 235436.

8 J. Lee, J. C. Park and H. Song, Adv. Mater., 2008, 20, 1523.

9 R. Singh, R. Verma, A. Kaushik, G. Sumana, S. Sood, R. K. Gupta and B. Malhotra, Biosens. Bioelectron., 2011, 26, 2967-2974.

10 H. Xu, J. Xu, Z. Zhu, H. Liu and S. Liu, Macromolecules, 2006, 39, 8451-8455.

11 P. Zhang, C. Shao, Z. Zhang, M. Zhang, J. Mu, Z. Guo and Y. Liu, Nanoscale, 2011, 3, 3357-3363.

12 M. Sawangphruk, M. Suksomboon, K. Kongsupornsak, J. Khuntilo, P. Srimuk, Y. Sanguansak, P. Klunbud, P. Suktha and P. Chiochan, J. Mater. Chem. A, 2013, 1, 9630-9636.

13 B. Wang, K. Chen, S. Jiang, F. Reincke, W. Tong, D. Wang and C. Gao, Biomacromolecules, 2006, 7, 1203-1209.

14 Y. Zhang and D. Rochefort, J. Microencapsulation, 2012, 29, 636-649.

15 H. Yi, L.-Q. Wu, W. E. Bentley, R. Ghodssi, G. W. Rubloff, J. N. Culver and G. F. Payne, Biomacromolecules, 2005, 6, 2881-2894.

16 M. M. Ayad, N. Salahuddin and I. M. Minisy, Des. Monomers Polym., 2014, 17, 795-802.

17 A. G. Yavuz, A. Uygun and V. R. Bhethanabotla, Carbohydr. Polym., 2010, 81, 712-719.

18 C. K. Choo, X. Y. Kong, T. L. Goh, G. C. Ngoh, B. A. Horri and B. Salamatinia, Carbohydr. Polym., 2016, 138, 16-26.

19 L. Deng, Q. Li, S. A. Al-Rehili, H. Omar, A. Almalik, A. Alshamsan, J. Zhang and N. M. Khashab, ACS Appl. Mater. Interfaces, 2016, 8, 6859-6868.

20 Y. Chen, Y. Zhang, F. Wang, W. Meng, X. Yang, P. Li, J. Jiang, H. Tan and Y. Zheng, Mater. Sci. Eng., C, 2016, 63, 18-29.

21 J. Upadhyay, A. Kumar, K. Gupta and M. Mandal, Carbohydr. Polym., 2015, 132, 481-489.

22 S. Varshney, K. Singh, A. Ohlan, V. Jain, V. Dutta and S. Dhawan, J. Alloys Compd., 2012, 538, 107-114.

23 J. Lee, H. Kang, S. Kee, S. H. Lee, S. Y. Jeong, G. Kim, J. Kim, S. Hong, H. Back and K. Lee, ACS Appl. Mater. Interfaces, 2016, 8, 6144-6151.

24 Q. Wei, M. Mukaida, K. Kirihara, Y. Naitoh and T. Ishida, ACS Appl. Mater. Interfaces, 2016, 8, 2054-2060.

25 S. Cao, N. Han, J. Han, Y. Hu, L. Fan, C. Zhou and R. Guo, ACS Appl. Mater. Interfaces, 2016, 8, 6040-6050.

26 U. Bogdanovic, I. A. Pasti, G. Ciric-Marjanovic, M. Mitric, S. P. Ahrenkiel and V. V. Vodnik, ACS Appl. Mater. Interfaces, 2015, 7, 28393-28403.

27 A. Drelinkiewicz, A. Zięba, J. Sobczak, M. Bonarowska, Z. Karpiński, A. Waksmundzka-Góra and J. Stejskal, React. Funct. Polym., 2009, 69, 630-642. 
28 P. Hamidi, R. Ojani, H. Razmi and I. Razavipanah, J. Iran. Chem. Soc., 2015, 12, 667-676.

29 R. Kosydar, M. Goral, A. Drelinkiewicz and J. Stejskal, Chem. Pap., 2013, 67, 1087-1095.

30 I. Sapurina, J. Stejskal, I. Šeděnková, M. Trchová, J. Kovářová, J. Hromádková, J. Kopecká, M. Cieslar, A. A. El-Nasr and M. M. Ayad, Synth. Met., 2016, 214, 14-22.

31 U. Mandi, A. S. Roy, B. Banerjee and S. M. Islam, RSC Adv., 2014, 4, 42670-42681.

32 C. Tian, Y. Du, P. Xu, R. Qiang, Y. Wang, D. Ding, J. Xue, J. Ma, H. Zhao and X. Han, ACS Appl. Mater. Interfaces, 2015, 7, 20090-20099.

33 Y. Dong, Z. Zhao, Z. Wang, Y. Liu, X. Wang and J. Qiu, ACS Appl. Mater. Interfaces, 2015, 7, 2444-2451.

34 G. M. Xiong, Y. Z. Yap and C. Choong, Nanomedicine, 2016, 11, 749-765.

35 J. Chen, J. Xu, K. Wang, X. Qian and R. Sun, ACS Appl. Mater. Interfaces, 2015, 7, 15641-15648.

36 M. Bhaumik, T. Y. Leswifi, A. Maity, V. Srinivasu and M. S. Onyango, J. Hazard. Mater., 2011, 186, 150-159.

37 M. Ayad, N. Salahuddin, A. Fayed, B. P. Bastakoti, N. Suzuki and Y. Yamauchi, Phys. Chem. Chem. Phys., 2014, 16, 21812 21819.

38 M. M. Ayad and E. Zaki, Appl. Surf. Sci., 2009, 256, 787-791. 39 S. Pandey and S. B. Mishra, Carbohydr. Polym., 2014, 113, 525-531.

40 M. Ayad, A. Rehab, I. El-Hallag and W. Amer, Eur. Polym. J., 2007, 43, 2540-2549.

41 M. M. Ayad, W. A. Amer and M. Whdan, J. Appl. Polym. Sci., 2012, 125, 2695-2700.

42 S. Laurent, D. Forge, M. Port, A. Roch, C. Robic, L. Vander Elst and R. N. Muller, Chem. Rev., 2008, 108, 2064-2110.

43 B. Ma, M. Wang, D. Tian, Y. Pei and L. Yuan, RSC Adv., 2015, 5, 41639-41645.

44 H. Nersisyan, J. Lee, H. Son, C. Won and D. Maeng, Mater. Res. Bull., 2003, 38, 949-956.

45 M. M. Ayad, N. Prastomo, A. Matsuda and J. Stejskal, Synth. Met., 2010, 160, 42-46.

46 A. Murugadoss and A. Chattopadhyay, Nanotechnology, 2007, 19, 015603.

47 L. Gai, X. Han, Y. Hou, J. Chen, H. Jiang and X. Chen, Dalton Trans., 2013, 42, 1820-1826.
48 M. Trchová, I. Šeděnková, E. Tobolková and J. Stejskal, Polym. Degrad. Stab., 2004, 86, 179-185.

49 M.-H. Hsiao, Q. Mu, Z. R. Stephen, C. Fang and M. Zhang, ACS Macro Lett., 2015, 4, 403-407.

50 E. Khor and J. L. H. Whey, Carbohydr. Polym., 1995, 26, 183187.

51 S. Xuan, Y.-X. J. Wang, J. C. Yu and K. C.-F. Leung, Langmuir, 2009, 25, 11835-11843.

52 M. Helmi Rashid Farimani, N. Shahtahmassebi, M. Rezaee Roknabadi and N. Ghows, Nanomed. J., 2013, 1, 71-78.

53 A. Dolatkhah and L. D. Wilson, ACS Appl. Mater. Interfaces, 2016, 8, 5595-5607.

54 N. Gavade, A. Kadam, M. Suwarnkar, V. Ghodake and K. Garadkar, Spectrochim. Acta, Part A, 2015, 136, 953-960.

55 J. Du and C. Jing, J. Colloid Interface Sci., 2011, 358, 54-61.

56 J. Sun, S. Zhou, P. Hou, Y. Yang, J. Weng, X. Li and M. Li, J. Biomed. Mater. Res., Part A, 2007, 80, 333-341.

57 S. Saha, A. Pal, S. Kundu, S. Basu and T. Pal, Langmuir, 2009, 26, 2885-2893.

58 M. Govarthanan, Y.-S. Seo, K.-J. Lee, I.-B. Jung, H.-J. Ju, J. S. Kim, M. Cho, S. Kamala-Kannan and B.-T. Oh, Artif. Cells, Nanomed., Biotechnol., 2016, 44, 1878-1882.

59 B. Ajitha, Y. A. K. Reddy, S. Shameer, K. Rajesh, Y. Suneetha and P. S. Reddy, J. Photochem. Photobiol., B, 2015, 149, 84-92.

60 W. Zhang, J. Chen, W. Wang, L. Hao, Y. Ni, C. Lu and Z. Xu, Results Phys., 2016, 6, 606-613.

61 M. Liang, R. Su, W. Qi, Y. Yu, L. Wang and Z. He, J. Mater. Sci., 2014, 49, 1639-1647.

62 Z. D. Pozun, S. E. Rodenbusch, E. Keller, K. Tran, W. Tang, K. J. Stevenson and G. Henkelman, J. Phys. Chem. C, 2013, 117, 7598-7604.

63 Y. Xue, X. Lu, X. Bian, J. Lei and C. Wang, J. Colloid Interface Sci., 2012, 379, 89-93.

64 K. Esumi, R. Isono and T. Yoshimura, Langmuir, 2004, 20, 237-243.

65 Y. Chi, Q. Yuan, Y. Li, J. Tu, L. Zhao, N. Li and X. Li, J. Colloid Interface Sci., 2012, 383, 96-102.

66 K. M. Manesh, A. I. Gopalan, K.-P. Lee and S. Komathi, Catal. Commun., 2010, 11, 913-918.

67 X. Zhang, W.-X. Zhi, B. Yan and X.-X. Xu, Powder Technol., 2012, 221, 177-182. 